\title{
A MENU ON OUTPUT GAP ESTIMATION 2017 METHODS
}

this - Alvarez and Ana Gomez- yoscos.

Documentos de Trabajo. N. 1720

BANCODE ESPAÑA

Eurosistema

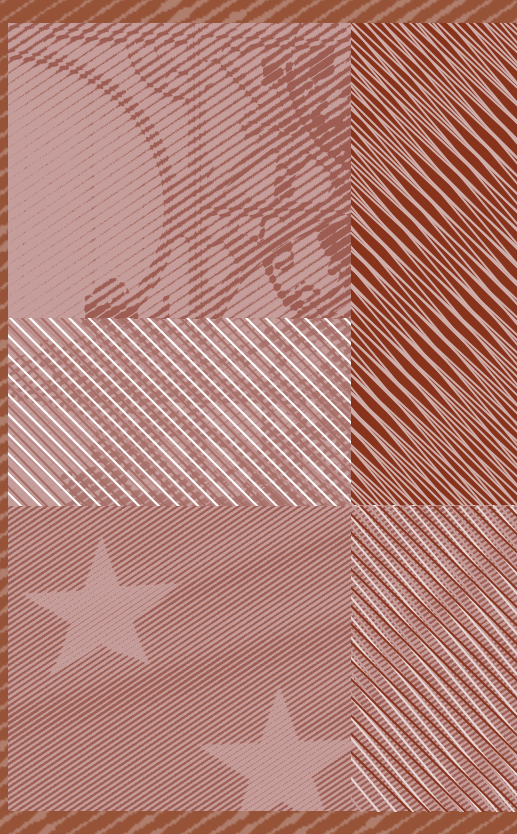


A MENU ON OUTPUT GAP ESTIMATION METHODS 


\section{A MENU ON OUTPUT GAP ESTIMATION METHODS}

Luis J. Álvarez (") and Ana Gómez-Loscos (")

BANCO DE ESPAÑA

(*) Corresponding author. Banco de España, Alcalá, 48, 28014 Madrid (Spain). Tel: +34 91 3385042, fax: +34 91 3385193 and email: ljalv@bde.es.

$\left.{ }^{* \star}\right)$ Banco de España, Alcalá, 48, 28014 Madrid (Spain). Tel: +34 91 3385817, fax: +34 913385193 and email: agomezloscos@bde.es. 
The Working Paper Series seeks to disseminate original research in economics and finance. All papers have been anonymously refereed. By publishing these papers, the Banco de España aims to contribute to economic analysis and, in particular, to knowledge of the Spanish economy and its international environment.

The opinions and analyses in the Working Paper Series are the responsibility of the authors and, therefore, do not necessarily coincide with those of the Banco de España or the Eurosystem.

The Banco de España disseminates its main reports and most of its publications via the Internet at the following website: http://www.bde.es.

Reproduction for educational and non-commercial purposes is permitted provided that the source is acknowledged.

(c) BANCO DE ESPAÑA, Madrid, 2017

ISSN: 1579-8666 (on line) 


\section{Abstract}

This paper presents a survey of output gap modeling techniques, which are of special interest for policy making institutions. We distinguish between univariate -which estimate trend output on the basis of actual output, without taking into account the information contained in other variables-, and multivariate methods -which incorporate useful information on some other variables, based on economic theory. We present the main advantages and drawbacks of the different methods.

Keywords: output gap, potential output, business cycle, trend output, survey.

JEL Classification: E32, O4. 


\section{Resumen}

En este trabajo se presenta una revisión de las técnicas de modelación del output gap (brecha de producción), que son de especial interés para diferentes instituciones en la formulación de políticas. Se distingue entre procedimientos univariantes - que estiman la producción tendencial a partir de la producción en términos reales, pero sin tener en cuenta la información contenida en otras variables - y métodos multivariantes - que incorporan información útil sobre algunas otras variables, de acuerdo con la teoría económica. Se exponen las principales ventajas e inconvenientes de los diferentes métodos.

Palabras clave: output gap, producto potencial, survey, ciclo económico, producción tendencial.

Códigos JEL: E32, O4. 


\section{Introduction}

There are several reasons behind the current interest in the estimation of the output gap by central banks, government institutions and international organisations ${ }^{1}$. First, the severity of the Great Recession and the subsequent slow recovery -few advanced economies have returned to pre-crisis growth rates despite years of near-zero interest rates- has rekindled the interest in estimating trend growth, in line with the secular stagnation hypothesis [Summers (2014)]. Second, measures of the size of the output gap are used as indicators of inflationary pressures in e.g. Phillips curve models. Third, in a moment in which many countries are undergoing fiscal consolidation, output gap measures are needed to estimate cyclically adjusted government budget balances, a useful indicator of fiscal policy stance. Fourth, the monetary policy literature has given much attention to the idea that Central Banks follow a so-called Taylor rule involving the output gap when setting interest rates.

One problem in this context is that data on trend output and the output gap are not directly observable, so that economic policy must be based on estimates. Theoretically, there exist an infinite number of possibilities of breaking down an economic series into a trend and a cyclical component and neither economic theory nor econometrics suggest a unique definition of trend. This has led to a proliferation of techniques for measuring business cycles and potential output. The aim of this paper is to present a menu of available estimation methods, presenting their main advantages and drawbacks.

The concept of potential output may be seen from different angles. From a purely statistical perspective, it can be seen as the trend or smooth component of the actual output series. From an economic point of view, potential output is often seen as characterising the sustainable (i.e. consistent with stable inflation) aggregate supply capabilities of the economy. Alternatively, potential output could be defined as the level of output attainable when making full use of all factors of production. Finally, natural output can be associated with flexible prices [Kiley (2013)].

Broadly speaking, existing approaches may be classified into two categories. On the one hand, univariate techniques estimate trend output on the basis of actual output, without taking into account the information contained in other variables. These procedures are generally simple and do not require assumptions about the structure of the economy. On the other hand, multivariate approaches incorporate useful information on some other variables, employing relationships established by economic theory, such as production functions or Phillips curves. While the use of economic theory in guiding the estimation process is attractive, it has to be acknowledged that views on the structure of the economy may differ across researchers and that some controversy may emerge on the validity of results.

After this introduction, this paper is structured as follows. In section 2 univariate approaches are described, multivariate methods are discussed in section 3 and section 4 concludes.

1. Cotis et al. (2004) examine the benefits and pitfalls of different estimation methods from a policy perspective. 


\section{Univariate approaches}

Univariate approaches can be classified depending on whether they use filters or models. To emphasise that trends and cyclical components differ according to the approach used to estimate them, we use the following notation. For a time series (or vector of time series) $z_{t}$ the trend (or vector of trends) at time $\mathrm{t}$ is given by $T_{t}^{X X}\left(z_{t}\right)$, where the superscript $\mathrm{XX}$ represents an abbreviation of the name of the approach employed, which appears within brackets in the corresponding section title. An analogous convention $C_{t}^{X X}\left(z_{t}\right)$ is used for the cyclical component. Furthermore, throughout the paper $y_{t}$ denotes the logarithm of output.

\subsection{Filtering approaches}

\subsubsection{THE HODRICK-PRESCOTT FILTER [HP]}

The filtering method introduced in macroeconomics by Hodrick and Prescott (1997) has a long history of use, since Leser (1961) seminal work. The underlying assumptions of this approach are that the trend is stochastic and varies smoothly over time.

The method may be rationalised from different perspectives: First, the original motivation is to obtain a trend balancing its smoothness and its fit to the original series by solving the following minimisation problem:

$$
T_{t}^{H P}\left(y_{t}\right)=\underset{\left\{y_{t}^{T}\right\}}{\operatorname{argmin}} \sum_{t=1}^{T}\left(y_{t}-y_{t}^{T}\right)^{2}+\lambda \sum_{t=3}^{T}\left(\Delta^{2} y_{t}^{T}\right)^{2}
$$

The first term shows the fit of the trend to the original series, whereas the second indicates the degree of smoothness, proxied by its second difference. The parameter $\lambda$, which has to be chosen, penalises fit versus smoothness. The higher is $\lambda$ the smoother is the trend. ${ }^{2}$

The solution to the minimisation problem is given by:

$$
T^{H P}(y)=\left(I+\lambda A^{\prime} A\right)^{-1} y
$$

where $A=\left(\begin{array}{cccccccc}1 & -2 & 1 & 0 & \cdots & 0 & 0 & 0 \\ 0 & 1 & -2 & 1 & \cdots & 0 & 0 & 0 \\ \vdots & \vdots & \vdots & \vdots & \cdots & \vdots & \vdots & \vdots \\ 0 & 0 & 0 & 0 & \cdots & 1 & -2 & 1\end{array}\right)$

$$
T^{H P}(y)=\left(T_{1}^{H P}(y), T_{2}^{H P}(y), \cdots, T_{T}^{H P}(y)\right)^{\prime} \text { and } y=\left(y_{1}, y_{2}, \cdots, y_{T}\right)^{\prime} \text {, so that HP trend }
$$
is a linear function of the series.

Second, the HP method may be considered as a high-pass filter [Prescott (1986)] that can be written [King and Rebelo (1993)] as:

2. If $\lambda=0$ only the fit is taken into account, and the trend equals the original series. Alternatively, if $\lambda \rightarrow \infty$ only smoothness is considered, the second difference of the trend has to be equal to zero and, therefore, the trend is a linear function of time. 


$$
C(L)=\frac{\lambda(1-L)^{2}(1-F)^{2}}{1+\lambda(1-L)^{2}(1-F)^{2}}
$$

where $L$ is the lag operator $\left[L z_{t} \equiv z_{t-1}\right]$ and $\mathrm{F}$ is the forward operator $\left[F z_{t} \equiv z_{t+1}\right]$ Hence, the HP filter is capable of rendering stationary any integrated process up to the fourth order. Moreover, the expression also shows that the cyclical component at time t depends on the past, present and future of the series. The gain function of the cyclical component filter has the following form:

$$
G^{H P}(\omega)=\frac{4 \lambda(1-\cos (\omega))^{2}}{1+4 \lambda(1-\cos (\omega))^{2}}
$$

Therefore, the cyclical component places zero weight on the zero frequency [ $G^{H P}(0)=0$ ] and close to unit weight on high frequencies $G^{H P}(\pi)=16 \lambda /(1+16 \lambda)$. The filter damps low frequency movements and leaves high frequency movements barely untouched. Moreover, increasing $\lambda$ shifts the gain function upward, moving a given frequency's gain closer to unity (Figure 1).

Figure 1

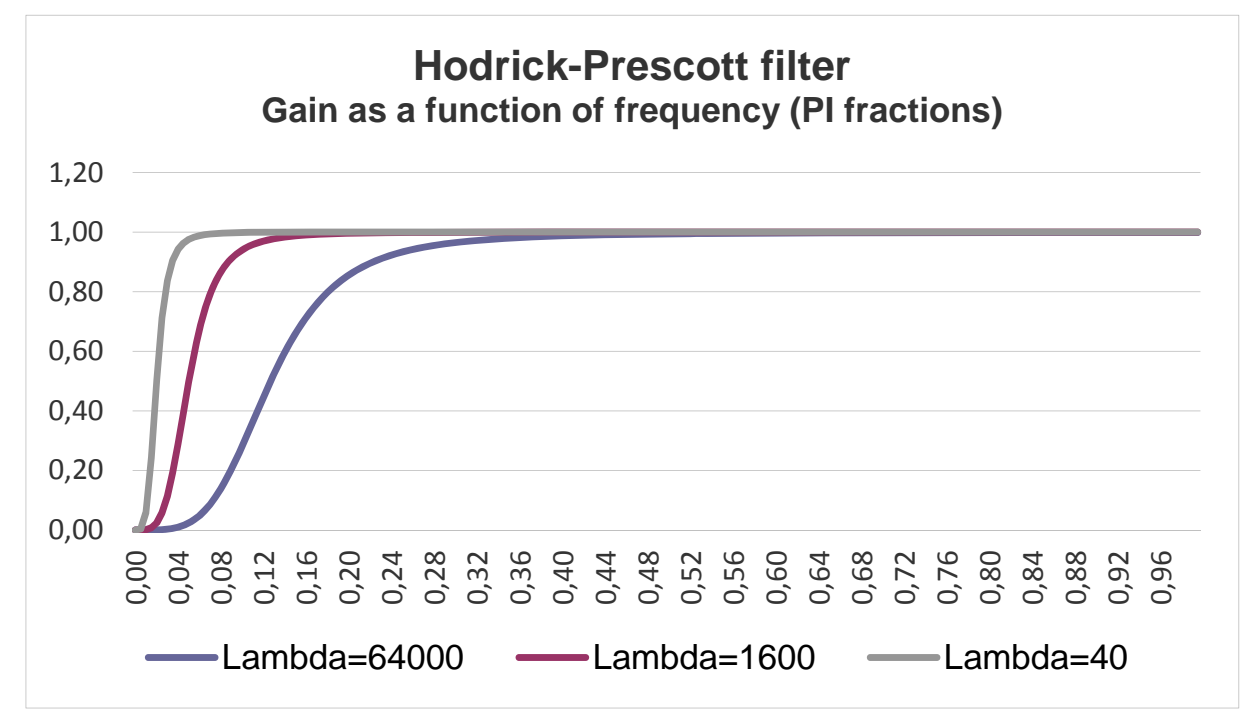

Third, the HP filter may also be rationalised as the optimal solution to a signal-extraction problem. From this perspective, Harvey and Jaeger (1993) show that the HP filter is the optimal linear estimator of the trend $\left(\tau_{t}\right)$ in the basic structural time-series model:

$$
y_{t}=\tau_{t}+\varepsilon_{t} \quad \varepsilon_{t} \sim \text { i.i.d.N }\left(0, \sigma_{\varepsilon}^{2}\right)
$$

where

$$
\begin{array}{ll}
\tau_{t}=\tau_{t-1}+\beta_{t-1}+\eta_{t} & \eta_{t} \sim \text { i.i.d. } \mathrm{N}\left(0, \sigma_{\eta}^{2}\right) \\
\beta_{t}=\beta_{t-1}+\zeta_{t} & \zeta_{t} \sim \text { i.i.d. } \mathrm{N}\left(0, \sigma_{\zeta}^{2}\right)
\end{array}
$$

and 


$$
\lambda=\frac{\sigma_{\varepsilon}^{2}}{\sigma_{\zeta}^{2}}
$$

Notice, however, that this rationalisation has the following assumptions: i) the series $y_{t}$ is integrated of order 2; ii) the cyclical component is a white noise process; and iii) that the chosen value of the parameter $\lambda$ corresponds to the ratio of the variance of the irregular component to the variance of the innovation in the trend component. ${ }^{3}$

Fourth, the HP filter may be regarded as a member of the Butterworth family of filters [Gómez (2001)]. Specifically, the gain of the two-sided Butterworth filter when based on the sine function (BFS) is given by:

$$
G^{B F S}(\omega)=\frac{1}{1+\left(\frac{\sin (\omega / 2)}{\sin \left(\omega_{.5} / 2\right)}\right)^{2 d}}
$$

This filter depends on two parameters $\omega_{.5}$, the frequency for which the gain equals one half and the integer number $d$, where larger values of $d$ produce sharper filters. Notice that when $d$ equals 2 this is the gain of the HP filter. This expression also suggests that, in general, there is a Butterworth filter that is more appropriate than the HP filter to estimate a cycle.

The HP filter has some drawbacks. First, $\lambda$ has to be specified beforehand and depending on the chosen rationalisation of the filter a different value of $\lambda$ may be justified. In fact, if one uses the minimisation approach the determination of $\lambda$ may be seen as arbitrary. If a signal extraction approach is used, then the value of $\lambda$ should be estimated from sample data. The interpretation of the HP filter as a high-pass filter suggests an objective way of determining $\lambda$. The value of 1600 typically chosen for applications with quarterly data ${ }^{4}$ may be rationalised as a high-pass filter that captures fluctuations with a period shorter than 8 years [Prescott (1986)]. The Butterworth filter interpretation gives some insight as to how to select $\lambda$. Indeed, the formula $\lambda=\left[2 \sin \left(\omega_{.5} / 2\right)\right]^{-2 d}$, where $d=2$ for the HP filter, gives us the relationship between $\lambda$ and the frequency $\omega_{c}$ for which the gain of the filter is 0.5 . This would suggest using 6.6 with annual data $^{5}$ [Gómez (2001)].

The second drawback of the HP filter is that it induces spurious cycles in series with the typical spectral shape. In fact, when applied to difference-stationary series point out that the HP filter does not operate like a high pass filter [Cogley and Nason (1995)]. In this case, the filter is equivalent to a two-step linear filter: difference the data to make them stationary and then smooth the differenced data with an asymmetric moving average, so that the filter can generate business cycle periodicity and comovement.

3. Trimbur (2006) develops a Bayesian generalisation of the Hodrick Prescott filter, in which a prior density is specified on $\lambda$. This method ensures an appropriate degree of smoothness in the estimated trend while allowing for uncertainty.

4. With annual data, Hassler et al. (1994) and Baxter and King (1999) point out that results obtained with $\lambda=10$ and annual data are similar to those obtained with $\lambda=1600$ and quarterly data.

5. Ravn and Uhlig (2002) find that $\lambda$ should be adjusted by multiplying it with the fourth power of the frequency ratio. That would lead to 6.25 for annual data. Indeed, Maravall and del Rio (2007) show that this empirical rule turns out to be a first order Taylor series approximation to the criterion of preserving the period corresponding to the frequency for which the filter gain is .5 . 
A third limitation is the poor behaviour of the HP filter for the most recent periods. To minimise this problem, many users of the HP filter have traditionally used series extended with the best available forecasts. ${ }^{6}$

On the advantages of the HP filter, it has been stressed that the method is simple and that it provides a uniform framework that can be applied to different countries in a timely manner. Since the method does not require subjective considerations, results can be easily reproduced.

\subsubsection{FLUCTUATIONS WITHIN A RANGE OF PERIODICITIES}

To some extent, the proliferation of techniques for measuring business cycles has resulted from a lack of a widely agreed upon definition of the business cycle, an issue which Burns and Mitchell (1946) viewed as central. In this sense, some proposals require the specification of the characteristics of the cyclical component. The main aim of these approaches is to design a filter which eliminates very slow moving (trend) components and very high frequency (irregular) components, while retaining intermediate (business cycles) components. The desired filter is what is known in the literature as an ideal band-pass filter, i.e. a filter which passes through components of a time series belonging to a pre-specified band of frequencies (pass band), while removing components at higher and lower frequencies. ${ }^{7}$ In formal terms, the ideal band-pass filter $\left(G_{I}^{B P}\right)$ has a gain function given by:

$$
G_{I}^{B P}(\omega)=\left\{\begin{array}{rr}
0 & \text { if }|\omega|<\omega_{p 1} \\
1 & \text { if } \omega_{p 1} \leq|\omega| \leq \omega_{p 2} \\
0 & \text { if }|\omega|>\omega_{p 2}
\end{array}\right.
$$

which means that frequencies belonging to the interval $\left\lfloor\omega_{p 1}, \omega_{p 2}\right\rfloor$ pass through the filter untouched, but all other frequencies are completely removed. $\omega_{p 1}$ defines the lower cutoff frequency and $\omega_{p 2}$ the upper cut-off frequency. For empirical applications, there is then a need to specify $\left\lfloor\omega_{p 1}, \omega_{p 2}\right\rfloor$.The most widespread definition is to consider cycles between 6 and 32 quarters [Baxter and King (1999)]. ${ }^{8}$

\subsubsection{BAXTER AND KING (1999) FILTER [BK]}

The aim of Baxter and King (1999) is to build the best linear band-pass filter that is constrained to produce stationary outcomes when applied to growing time series. ${ }^{9}$ The ideal band-pass filter requires an infinite-order moving average $b(L)=\sum_{j}^{\infty} b_{j}$. However, in empirical applications series are of finite length, ${ }_{k}$ o it is necessary to approximate the ideal filter with a finite symmetric moving average $a_{k}(L)=\sum_{j=-k}^{k} a_{j} L^{j}$

6. This practice is in line with Kaiser and Maravall (2001) results, which are confirmed by Mise et al. (2005). These authors show through simulation exercises that applying the HP filter to a series extended with ARIMA forecasts and backcasts generally provides a cycle estimator for recent periods that requires smaller revisions. This modification also improves the detection of turning points.

7. Christiano and Fitzgerald (2003) propose a different approximation to the ideal band-pass filter.

8. For example, Englund et al. (1992) define the business cycle in terms of fluctuations longer than 18 quarters but shorter than 32 quarters and Stock and Watson (1999) are interested in cyclical components of no less than 6 quarters in duration but fewer than 24 quarters.

9. See Stock and Watson (2005) for an application. 
To find the weights, Baxter and King (1999) solve the following constrained minimisation problem:

$$
\begin{array}{cc}
\underset{\left.\alpha_{j}\right\}}{\operatorname{Min}} & \int_{-\pi}^{\pi}\left|\beta(\omega)-\alpha_{k}(\omega)\right|^{2} d \omega \\
\text { s.t } & \alpha_{k}(0)=0
\end{array}
$$

where $\beta(\omega)$ denotes the gain function of the ideal band-pass filter, $\alpha_{k}(\omega)$ the gain function of the approximating filter and the gain of the approximating filter at frequency zero is zero, so that the filter will render stationary $I(2)$ stochastic processes.

From the first order conditions, the optimal solution is given by:

$$
\begin{gathered}
a_{j}=b_{j}+\phi \quad j=0,1, \cdots, k \text { where } \\
\qquad b_{j}=\left\{\begin{array}{cc}
\frac{\omega_{p 2}-\omega_{p 1}}{\pi} & j=0 \\
\text { where } & j=1,2, \cdots \\
\frac{\sin \left(j \omega_{p 2}\right)-\sin \left(j \omega_{p 1}\right)}{j \pi} b_{j}
\end{array}\right.
\end{gathered}
$$

The weights of the optimal approximation are obtained in two stages. First, weights $\left\{b_{j}\right\}$ corresponding to the ideal band-pass filter are computed, keeping the first $k+1$ ones. Second, a correction factor $\phi$ is added, which depends on the extent to which truncation distorts the desired behaviour at frequency zero. The cyclical component is obtained as:

$$
\begin{aligned}
& C_{t}^{B K}\left(y_{t}\right)=\sum_{j=-k}^{k} a_{j} L^{j} y_{t} \\
& \text { and its gain function is given by: } \\
& G^{B K}(\omega)=a_{0}+2 \sum_{j=1}^{k} a_{j} \cos (j \omega)
\end{aligned}
$$

which is represented in Figure 2. 
Figure 2

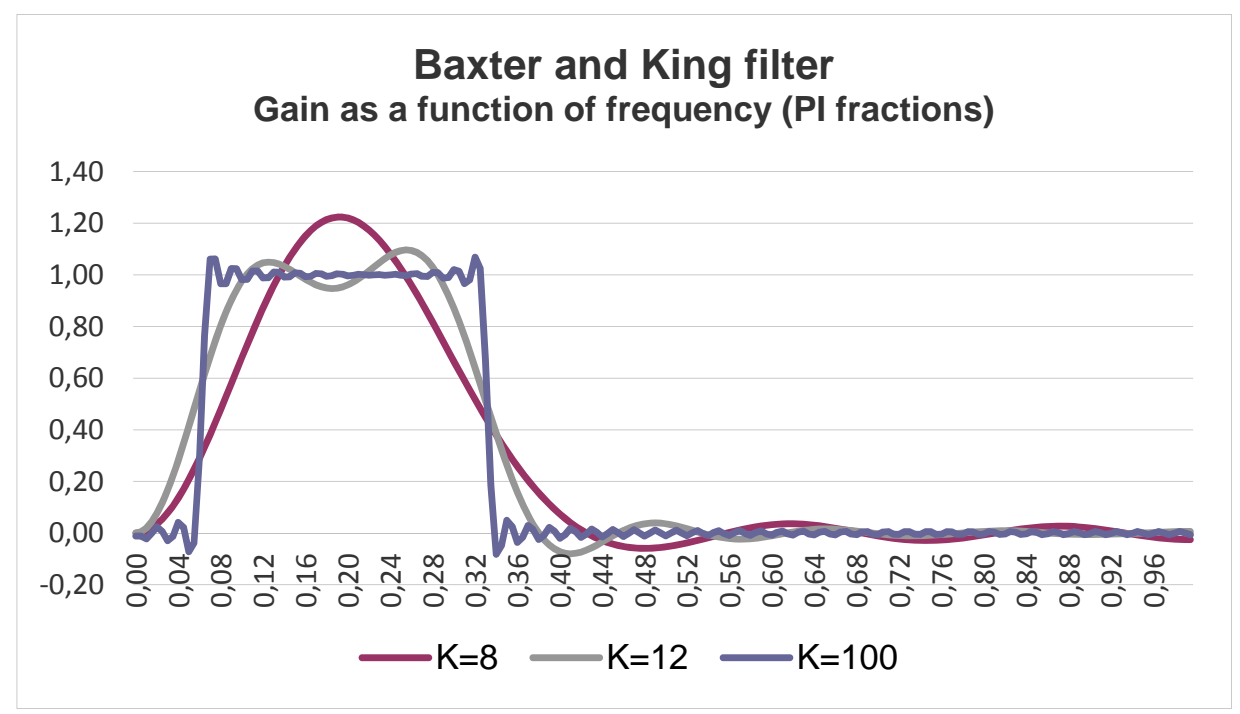

The following advantages of the BK filter may be stressed. First, the method is transparent over the range of frequencies it aims to extract. This contrasts with the determination of the smoothing parameter $\lambda$ of the HP filter. Second, it is straightforward to employ the filter to data with a frequency other than quarterly.

Among the drawbacks, it should be noted that the method involves losing $k$ observations at the beginning of the series and $\mathrm{k}$ at the end of the series. This problem could be mitigated with the use of a series extended with forecasts. Moreover, the gain of the BK filter oscillates around the gain of the ideal filter. As an additional drawback of the Baxter and King filter, Murray (2003) notes that the BK filter does not isolate the cycle properly for series with stochastic trends, since the first difference of the trend passes through the filter, so that the spectral properties of the cycle depend on the trend in the unfiltered series.

\subsubsection{BUTTERWORTH FILTERING [B]}

Butterworth filters are low-pass or band-pass filters. There are two families of Butterworth filters, which are based on the sine function (BFS) and the tangent function (BFT). The gain of the lowpass (LP) BFS filter is given by:

$$
G_{L P}^{B F S}(\omega)=\frac{1}{1+\left(\frac{\sin (\omega / 2)}{\sin \left(\omega_{.5} / 2\right)}\right)^{d}}
$$

where $\omega_{.5}$ is the frequency for which the gain of the filter equals one half and $d$ is an integer that controls the slope of the gain function. As noted above, the Hodrick Prescott filter is the low pass BFS, when $d$ equals 2 . The low pass BFT is obtained by replacing the sine function with the tangent function in the equation above. Note that $G_{L P}^{B F T}(\pi)=0$, but $G_{L P}^{B F S}(\pi) \neq 0$, so that BFS does not fully suppress high frequency fluctuations. 
BFS and BFT can be obtained as optimal (minimum mean squared) estimators of the signal in the signal $\left(s_{t}\right)$ plus noise $\left(n_{t}\right)$ model [Gómez (2001)]:

$$
y_{t}=s_{t}+n_{t}
$$

where $\Delta^{d} s_{t}=\theta_{s}(L) a_{t}$ and $a_{t}$ and $n_{t}$ are zero mean constant variance independent processes. In the case of BFS $\theta_{s}(L)=1$, so that $s_{t}$ is $\mathrm{IMA}(\mathrm{d}, 0)$ process, and in the case of BFT $\theta_{s}(L)=(1+L)^{d}$, so that $s_{t}$ is a $\mathrm{n} \operatorname{IMA}(\mathrm{d}, \mathrm{d})$ process.

Butterworth band-pass filters BPF $(L, F)$ in the time domain can be expressed as:

$$
\begin{aligned}
& \operatorname{BPF}(L, F)=\frac{\left(1-L^{2}\right)^{d}\left(1-F^{2}\right)^{d}}{\left(1-L^{2}\right)^{d}\left(1-F^{2}\right)^{d}+\lambda\left(1-\alpha L+L^{2}\right)^{d}\left(1-\alpha F+F^{2}\right)^{d}} \\
& \text { where } \alpha=\cos \left(\left(\omega_{p 2}+\omega_{p 1}\right) / 2\right) / \cos \left(\left(\omega_{p 2}-\omega_{p 1}\right) / 2\right), \lambda=\sigma_{\eta}^{2} / \sigma_{a}^{2} \text { and } \omega_{p 1} \text { and } \omega_{p 2}
\end{aligned}
$$
are the lower and upper limits of the band-pass, respectively. Note that larger values of $d$ produce sharper filters.

These Butterworth band-pass filters also admit a model-based interpretation. ${ }^{10}$ Specifically, Gómez (2001) shows that the band-pass BFT can be obtained ${ }^{11}$ as the best linear estimator, in the mean squared sense, of the signal in the signal-plus-noise model:

$$
y_{t}=s_{t}+\varepsilon_{t}
$$

where $s_{t}$ follows the model $\left(1-2 \cos \alpha L+L^{2}\right)^{d} s_{t}=\left(1-L^{2}\right)^{d} \eta_{t}$ and $\varepsilon_{t}$ and $\eta_{t}$ are white noise processes. Note that the autoregressive model for the signal has two complex roots of unit modulus.

Figure 3

\section{Butterworth and Baxter and King band pass filters \\ Gain as a function of frequency (PI fractions)}

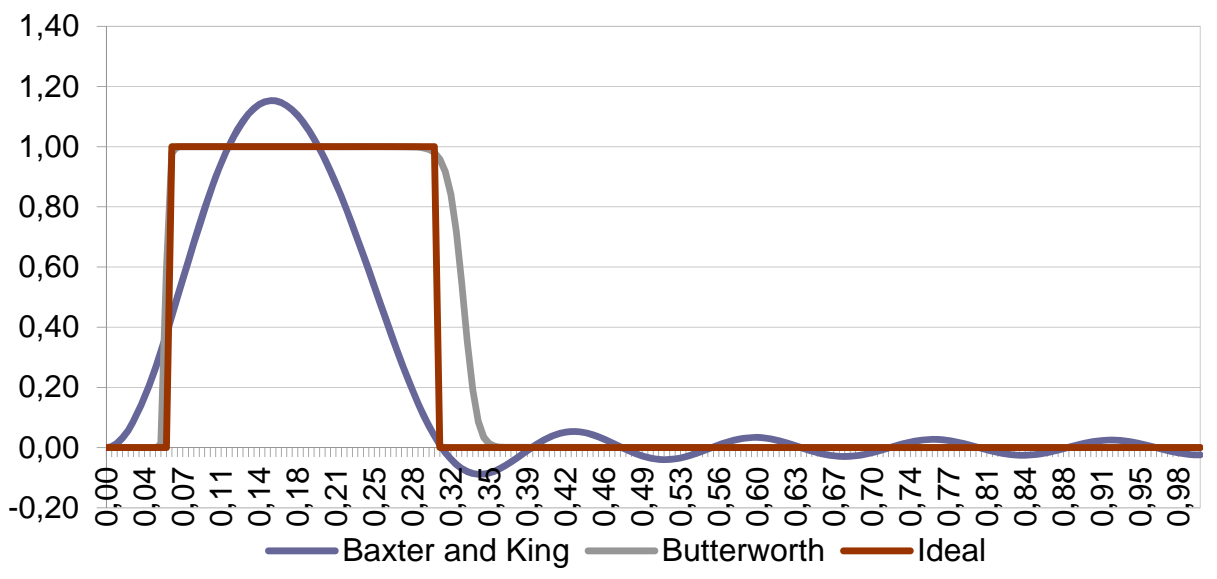

10. Valle e Azevado et al. (2006) propose a multivariate generalization of a band-pass filter. 11. Harvey and Trimbur (2003) give a model-based interpretation for band pass BFS filters. 
The use of Butterworth band-pass filters has two main advantages with respect to the usual finite moving average filters, such as Baxter and King (1999). First, because rational functions are used instead of polynomials in the lag operator, a better approximation to an ideal gain function is possible (Figure 3). Second, the number of forecasts and backcasts required for the finite sample implementation of Butterworth filters is much smaller than for finite moving average filters.

\subsubsection{WAVELET-BASED METHODS [W]}

Donoho (1993) introduced a method called wavelet denoising or wavelet shrinkage that has been applied by e.g. Aguiar-Conraria and Soares (2011) and Tiwari et al. (2014) to obtain measures of the output gap. This method may be thought of as a generalisation of Fourier analysis. Traditional Fourier analysis does not account for variation through time of the frequency components of a series. In contrast, wavelet analysis is able to assess through the relative importance of cycles of different duration, so it is more suitable to study irregular series.

The idea of this method is analogous to a series of low pass filters: large wavelets encode the general trend in output, whereas small wavelets characterise the details. Therefore, by filtering out the coefficients of the small wavelets it is possible to obtain the dominant features of a series by applying the inverse wavelet transform. To be more specific, the trend component of the output series is obtained through the following three steps.

First, the output series is first expressed as the orthogonal wavelet series:

$$
y_{t}=d_{o} \phi(t)+\sum_{j=0}^{n-1} \sum_{k=0}^{2^{j}-1} d_{j k} \psi_{j k}(t)
$$

and the coefficients of the wavelet representation $\left(d_{o}\right.$ and $\left.d_{j k}\right)$ are obtained. In this expression, $\varphi(t)$ is a father wavelet, also referred to as a scaling function that represents the smooth baseline of the series where, given a mother wavelet $\psi(t)$, an orthonormal $\left\{\psi_{j k}(t)\right\}$ basis is defined as:

$$
\psi_{j k}(t)=2^{j / 2} \psi\left(2^{j} t-k\right)
$$

where the parameters $\mathrm{j}$ and $\mathrm{k}$ dilate and translate the function.

Second, the wavelet coefficients are shrunk applying a thresholding non-linear transformation:

$$
\hat{d}_{j k}=\left\{\begin{array}{lll}
d_{j k} & \text { if } & \left|d_{j k}\right| \leq \kappa \\
0 & \text { if } & \left|d_{j k}\right|>\kappa
\end{array}\right.
$$

to eliminate the wavelet coefficients that are thought to correspond to business cycle frequencies. 
Third, the inverse wavelet transform is applied in order to obtain the measure of trend output:

$$
T^{W}\left(y_{t}\right)=\hat{d}_{o} \phi(t)+\sum_{j=0}^{n-1} \sum_{k=0}^{2^{j}-1} \hat{d}_{j k} \psi_{j k}(t)
$$

This filter has more degrees of freedom than a band-pass filter. It is not limited to a particular choice of wavelets, while the band-pass filter is defined exclusively in the space formed by sines and cosines. This could make the method more appealing since, at least theoretically, it would cope better with a changing economic structure. Second, the features of the filter can be modified according to the number of wavelet coefficients removed and the shrinkage threshold. Among its drawbacks, there exists a wide choice of wavelets and the methodology to select the most appropriate one depends on subjective considerations.

\subsection{Model-based approaches}

\subsubsection{LINEAR DETRENDING [LD]}

One simple method is to assume the trend is a linear function of time. ${ }^{12}$ The cyclical component emerges in this method as a residual from the trend line. Specifically,

$$
T_{t}^{L D}\left(y_{t}\right)=\alpha+\beta t
$$

where $y_{t}$ denotes the logarithm of output and $t$ denotes time.

The main virtue of this procedure lies in its simplicity. However, one undesirable implication is that the long-run evolution of a time series is a function of time. The idea that economic time series are better characterised by stochastic trends led to the development of a set of techniques aimed at taking into account this feature.

\subsubsection{A FORECASTING PERSPECTIVE. BEVERIDGE AND NELSON (1981) [BN]}

The Beveridge and Nelson (1981) procedure decomposes a non-stationary time series as the sum of a permanent and a transitory component. The trend component is defined in terms of the long-run forecast of output and the corresponding cyclical component has the interpretation as the negative of output growth in the excess of the normal growth that would be forecast given the current state of the economy.

The starting point of this approach is that many economic time series are well represented by an ARIMA process for which the first differences are a stationary process of autoregressive-moving average form. If we denote by $\Delta y_{t}$ the first difference of the logarithm of output, then:

$$
\Delta y_{t}=d+\frac{\theta_{q}(L)}{\phi_{p}(L)} \varepsilon_{t}=d+\psi(L) \varepsilon_{t}
$$

12. In empirical investigations segmented trends are often used [e.g. Drake and Mills (2010)]. This implies that trend growth is not constant over time, although it is constant inside particular time intervals. Segmented trends allow for the incidence of supply shocks, which may permanently alter both the level and trend growth rate of potential output. 
where $d$ is the mean of the process, $\varepsilon_{t} \sim$ i.i.d. $\mathrm{N}\left(0, \sigma_{\varepsilon}^{2}\right)$ and $\theta_{q}(L)$ and $\phi_{p}(L)$ are polynomials in the lag operator of orders $p$ and $q$, respectively, with roots outside the unit circle.

The following additive decomposition of $\Delta y_{t}$ into a stationary and a non-stationary component:

$$
\Delta y_{t}=d+\psi(1) \varepsilon_{t}+\widetilde{\psi}(L) \varepsilon_{t}
$$

where $\tilde{\psi}(L)=\psi(L)-\psi(1)$.

The sum of the first two terms on the right hand side represents the first difference of the trend component, which follows a random walk with drift, while the third term represents the first difference of the cyclical component.

$$
\begin{aligned}
& \Delta T_{t}^{B N}\left(y_{t}\right)=d+\psi(1) \varepsilon_{t} \\
& \Delta C_{t}^{B N}\left(y_{t}\right)=\tilde{\psi}(L) \varepsilon_{t}
\end{aligned}
$$

Beveridge and Nelson (BN) define the trend as the value the series would have if it were on its long-run time path in the current time period. This definition of trend is then the long-run forecast of the series adjusted for its mean rate of change. This trend may be expressed as a weighted average of the current and past values of the series $y_{t}$ :

$$
T_{t}^{B N}\left(y_{t}\right)=\frac{\theta_{q}(1)}{\phi_{p}(1)} \frac{\phi_{p}(L)}{\theta_{q}(L)} y_{t}
$$

This expression shows that future information will not modify the trend component and that the weights used to calculate the trend will differ depending on the stochastic properties of the series. ${ }^{13}$

Three drawbacks of the BN decomposition should be noted [Beveridge and Nelson (1981) and Canova (1998)]. First, since trend and cycle are driven by the same shock, the innovations to these components are perfectly correlated. This may not correspond to the conventional view about the behaviour of these components. Second, the trend component may be too "noisy", since the variance of the innovation in the permanent component may be larger than the innovation of the observed data. ${ }^{14}$ Third, it may be the case that different ARIMA models fit the data fairly well. However, because ARIMA models with similar short-run properties may have very different long-run properties, alternative specifications may lead to very different decompositions into trend and cycle.

13. Proietti and Harvey (2000) propose a Beveridge-Nelson smoother, which is two-sided signal extraction filter for trends This estimator is the optimal (minimum mean square error) estimator of the trend when the ARIMA model can be decomposed into an uncorrelated random walk and stationary cycle components.

14. Morley et al. (2003) show that the $B N$ decomposition is identical to that obtained with a structural time series model, once the restriction of uncorrelatedness between innovations in the trend and cyclical components is allowed for. Morley (2011) points out that these two models have very different implications in terms of the uncertainty about the measure of the permanent component. 


\subsubsection{A STRUCTURAL TIME SERIES APPROACH [STS]}

Univariate structural time series models are models that are set up in terms of unobserved components, which have a direct interpretation [see e. g. Harvey (1985)]. The whole model is handled within a unified statistical framework that produces optimal estimates with well-defined properties. A traditional formulation is the trend plus cycle plus irregular model

$$
y_{t}=\tau_{t}+\gamma_{t}+\varepsilon_{t}
$$

where $y_{t}$ is the logarithm of output, $\tau_{t}$ is a trend, $\gamma_{t}$ is a cycle, and $\varepsilon_{t}$ is an irregular component and all components are assumed to be uncorrelated with each other. Since a deterministic time trend seems too restrictive, in this type of models a more flexible approach is used by letting the level and slope parameters change over time. Specifically, these parameters are typically assumed to follow random walks. ${ }^{15}$

$$
\begin{aligned}
& \tau_{t}=\tau_{t-1}+\beta_{t-1}+\eta_{t} \\
& \beta_{t}=\beta_{t-1}+\zeta_{t}
\end{aligned}
$$

where $\eta_{t}$ and $\zeta_{t}$ are white noise processes with variances $\sigma_{\eta}^{2}$ and $\sigma_{\zeta}^{2}$.

The stochastic cycle is generated as:

$$
\begin{aligned}
& \gamma_{t}=\rho \cos \lambda \gamma_{t-1}+\rho \sin \lambda \gamma_{t-1}^{*}+v_{t} \\
& \gamma_{t}^{*}=-\rho \sin \lambda \gamma_{t-1}+\rho \cos \lambda \gamma_{t-1}^{*}+v_{t}^{*}
\end{aligned}
$$

where $\rho$ is a damping factor such that $0 \leq \rho<1, \lambda$ is the frequency of the cycle expressed in radians and $v_{t}$ and $v_{t}^{*}$ are white noise processes with variances $\sigma_{v}^{2}$ and $\sigma_{v^{*}}^{2}$, respectively. In general, the cyclical component is a stationary variable. ${ }^{16}$ Finally, the irregular component is also a white noise process with variance $\sigma_{\varepsilon}^{2}$.

Once the model is specified, it can be estimated by casting it in space-state form. The Kalman filter may then be used and the Kalman smoother allows the extraction of trend and cycles:

$$
T_{t}^{S T S}\left(y_{t}\right)=\hat{\tau}_{t} ; C_{t}^{S T S}\left(y_{t}\right)=\hat{\gamma}_{t}
$$

One drawback of this approach is that it assumes that output is integrated of order two. ${ }^{17}$ Most macroeconomists, however, consider that output growth is stationary. In practice, the standard STS often results in the irregular component disappearing, so that the cycle is quite noisy [Harvey et al. (2007)]. The reduced-form of this structural model is a restricted ARIMA $(2,2,4)$ model with some nonlinear restrictions on the coefficients. To the extent that the series under study departs from this ARIMA model, results with the STS model may be unreliable.

15. Note that the level and slope are allowed to evolve over time and that the deterministic trend is a limiting case in which these variances are zero.

16. This is the case provided that $0 \leq \rho<1$. In this case, the cyclical component follows an ARMA $(2,1)$ process.

17. This is a particular feature of the basic structural model. 
The STS is generalised in Harvey and Trimbur (2003). These authors propose a model with a stochastic trend of order $m$ (instead of the standard order 1 ) and a stochastic cycle of order $\mathrm{n}$ (instead of the standard order 1). They find that the generalised cyclical component provides a smoother, more clearly defined cycle. ${ }^{18}$

\subsubsection{MARKOV SWITCHING MODELS [MS]}

The Markov switching model, due to Hamilton (1989), divides the business cycle into two phases, negative trend growth and positive trend growth, with the economy switching back and forth according to a first order Markov process. Hamilton proposes modelling output as the sum of two independent unobserved components, one following a random walk with drift, which evolves according to a two-state Markov process, and the other following an autoregressive process with a unit root. Specifically, the output series is decomposed as

$$
y_{t}=\tau_{t}+\eta_{t}
$$

where the first component is assumed to follow a random walk with drift, which evolves according to a two-state Markov process

$$
\begin{array}{ll}
\tau_{t}=\tau_{t-1}+\alpha_{0}+\alpha_{1} S_{t} & \\
S_{t}=\{0,1\} & \operatorname{Prob}\left(S_{t}=0 \mid S_{t-1}=1\right)=1-p \\
\operatorname{Prob}\left(S_{t}=1 \mid S_{t-1}=1\right)=p & \operatorname{Prob}\left(S_{t}=0 \mid S_{t-1}=0\right)=1-q \\
\operatorname{Prob}\left(S_{t}=1 \mid S_{t-1}=0\right)=q &
\end{array}
$$

and the second component follows an ARIMA $(p, 1,0)$ process. In this model, $\Delta \tau_{t}$ need not change every period, in contrast with a STS model, even though $\Delta \tau_{t}$ follows an $\mathrm{AR}(1)$ process. The reason is that the innovation follows a discrete distribution instead of a Gaussian one.

The attractiveness of this specification comes from the fact that it allows for non-linear dynamics such as asymmetry. For estimation purposes a non-linear iterative filter is employed to obtain maximum likelihood estimates of population parameters.

An alternative possibility to deal with asymmetric behaviour is to employ the model by Kim and Nelson (1999). They propose modelling output as two independent unobserved components, ${ }^{19}$ one a stochastic trend with time-varying level and slope parameters, and the other following a mixture of symmetric and asymmetric shocks. Specifically, the output series is decomposed as:

$$
y_{t}=\tau_{t}+\eta_{t}
$$

18. This generalised model is studied from a Bayesian perspective in Harvey et al. (2007). This perspective allows flexible restrictions to be placed on key parameters, such as the period in the stochastic cycle and avoids fitting implausible models. 19. Sinclair (2010) develops an unobserved components model that allows for both asymmetric transitory movements and correlation between the permanent and transitory innovations. 
The stochastic trend follows a conventional specification:

$$
\tau_{t}=\tau_{t-1}+\beta_{t-1}+\eta_{t}
$$

and to allow for regime shifts or asymmetric deviations transitory shocks have the following specification:

$$
\begin{aligned}
& \phi(L) \eta_{t}=v_{t} S_{t}+\varepsilon_{t} \\
& S_{t}=\{0,1\}
\end{aligned}
$$

$$
\operatorname{Prob}\left(S_{t}=1 \mid S_{t-1}=1\right)=p \quad \operatorname{Prob}\left(S_{t}=0 \mid S_{t-1}=1\right)=1-p
$$

$$
\operatorname{Prob}\left(S_{t}=1 \mid S_{t-1}=0\right)=q \quad \operatorname{Prob}\left(S_{t}=0 \mid S_{t-1}=0\right)=1-q
$$

$v_{t}$ is an asymmetric, discrete shock (the size of the pluck) which is dependent on an unobserved Markov-switching state variable $S_{t}$ whose transition probabilities are specified above and which accounts for the persistence of normal or recession periods and $\varepsilon_{t}$ is a symmetric shock. During normal times, $S_{t}=0$ and the economy is near the potential or trend output. During recession times, $S_{t}=1$, the economy is hit by a large negative shock and firms use factors suboptimally and output is below its production frontier.

According to Friedman $(1964,1993)$, recessions are periods where output is hit by large negative transitory shocks, labelled plucks. Following the trough, output enters a high growth recovery phase, returning to the trend. Output then begins a normal, slower growth, expansion phase. Thus, Friedman's view is that recessions are entirely transitory deviations from trend, not movements in the trend itself. In this regard, Kim et al. (2005) have proposed a model with a post-recession bounce-back effect in the level of output. Their model is described as:

$$
\phi(L) \eta_{t}=\rho_{0}+\rho_{1} S_{t}+\delta \sum_{j=1}^{h} S_{t-j}+\varepsilon_{t}
$$

where $S_{t}$ is a latent first-order Markov switching process, which equals 1 in recessions. When $\delta=0$ the model collapses to Hamilton (1989), whereas if $\delta$ is positive, the summation term implies that GDP will be above average for some time after a recessionary regime, indicating the existence of a post-recession bounce back effect. This implies that a recessionary shock is less persistent than an expansionary one. 


\section{Multivariate approaches}

By their own nature, it is hard or even impossible to give univariate approaches a structural interpretation. Against this background, it seems natural to expand the information set used in the estimation of the output gap and employ multivariate approaches that can be given an economic interpretation. To this end, a variety of methods have been proposed in the literature, the most widespread of which are examined below.

\subsection{Okun's law [OL]}

In the short-run, when aggregate demand fluctuates and firms respond by adapting their output, they mostly resort to changes in their labour input. This results in a negative empirical relationship between fluctuations of output around its trend $C_{t}\left(y_{t}\right)$ and fluctuations of unemployment around its trend $C_{t}\left(u_{t}\right)$, which is known as Okun's law.

$$
C_{t}\left(y_{t}\right)=\alpha C_{t}\left(u_{t}\right)
$$

Although there are a number of reasons for which Okun's law is not expected to hold exactly, even in the short-run, such as productivity shocks, this empirical relationship generally provides a satisfactory approximation and, since Evans (1989), has been exploited by many authors to assess the cyclical position of the economy [e.g. Apel and Jansson (1999), Doménech and Gómez (2006)].

Evans (1989) uses a bivariate structural VAR to describe (the log difference of) output and unemployment dynamics. The identifying restriction is that output shocks contemporaneously cause the unemployment rate. This means that the negative correlation between $\Delta y_{t}$ and $u_{t}$ is attributed to an Okun's law equation, in which $\Delta y_{t}$ is weakly exogenous and the unemployment equation is interpreted as a dynamic version of Okun's law. The corresponding structural model is:

$$
\begin{aligned}
& \Delta y_{t}=\alpha(L) \Delta y_{t-1}+\beta(L) u_{t-1}+e_{y, t} \\
& u_{t}=\gamma(L) y_{t}+\delta(L) \Delta y_{t-1}+\eta(L) u_{t-1}+e_{u, t} \\
& \text { where }\left(e_{y, t}, e_{u, t}\right)^{\prime} \text { are orthogonal structural shocks. }
\end{aligned}
$$

Based on this model, Evans (1989) develops a cyclical measure based on Okun's law. Okun defined potential output as the level of output that would yield an unemployment rate equal the conditional mean of the unemployment rate. To obtain the cyclical measure, it is assumed that the sequence of future output growth rates is such that unemployment remains at its unconditional mean level and that the unemployment equation is invariant to these changes. If we denote $\Delta y_{t}^{O L}$ as the level of output conditional of unemployment being at its unconditional mean, then a definition of the output gap, à la Beveridge and Nelson, is given by:

$$
C_{t}^{O L}\left(y_{t}\right)=\sum\left(E\left(\Delta y_{t}\right)-\Delta y_{t}^{O L}\right)
$$


Here, the extra growth available is measured along an unconditional mean unemployment rate, rather than along the path corresponding to the normal dynamic response of the economy.

Among the drawbacks of the Okun's law, it has been pointed out that the unemployment rate is just a proxy variable for all the ways in which output -which depends on labour, capital and technology-, is affected by idle resources. Furthermore, the unemployment rate is but one factor in determining the total amount of labor used as an input; other factors include the fraction of the population that is in the labor force and the number of hours that employed workers are used. Finally, Blanchard and Quah (1989) argue that Okun's law coefficient is mongrel since the relationship between output and unemployment depends on whether shocks are demand or supply side.

\subsection{A production function approach [PF]}

The traditional production function approach is intended to provide a comprehensive and consistent economic framework for measuring potential output and the output gap. The method explicitly models output in terms of underlying factor inputs, and not just labour, as in an Okun's law approach, and involves specifying and estimating production functions that link output to capital, labour and total factor productivity. Potential output is then calculated as the level of output that results when the rates of capacity utilisation are normal, when labour input is consistent with the natural rate of unemployment, and when total factor productivity is at its trend level. This method is currently being used by central banks and international organizations.

The method first requires choosing an appropriate specification for the production function. This allows for an explicit accounting for growth in terms of the contributions of factor inputs and a residual driven by total factor productivity. In what follows we describe, for illustrative purposes, the production function method as used by the European Commission [Havik et al. (2014)]. Potential output is computed on the basis of a two-factor Cobb-Douglas production function with constant returns to scale. Using this production function, the measure of potential output is obtained by combining a measure of trend productivity with the actual capital stock and estimates of potential employment. The chosen measure of potential employment is defined as the level of labour resources that might be employed without resulting in additional inflation. More specifically, the production function is assumed to be of the Cobb-Douglas form:

$$
y_{t}=\lambda_{t}+(1-\alpha) k_{t}+\alpha l_{t}
$$

where $\lambda_{t}$ denotes the logarithm of total factor productivity, $k_{t}$ the logarithm of capital, $l_{t}$ the logarithm of labour input and $\alpha$ is the elasticity of labour with respect to output, which can be estimated from the wage share under the assumption of constant returns and perfect competition. Potential output is obtained from:

$$
T_{t}^{P F}\left(y_{t}\right)=T_{t}^{K F}\left(\lambda_{t}\right)+(1-\alpha) k_{t}+\alpha T_{t}^{N A W R U}\left(l_{t}\right)
$$

where $T_{t}^{K F}\left(\lambda_{t}\right)$ is a measure of the logarithm of trend factor productivity obtained with a bivariate Kalman Filter which exploits the link between the TFP cycle and the degree of capacity utilisation and $T_{t}^{N A W R U}\left(l_{t}\right)$ is a measure of trend employment defined as the level of labour input that might be employed without additional inflation.

It has been stressed that the PF approach has a number of advantages. For instance, it can provide a broad and coherent assessment of the economic outlook. Furthermore, it allows 
for an explicit accounting for growth in terms of contributions of capital, labour and total factor productivity. Besides, it is possible to estimate the impact of current or projected developments on future levels of potential output, although this requires being able to project potential labour and trend TFP.

There are, however, a number of drawbacks. Some assumptions on the structure of the economy need to be made and they may not fully correspond to reality. For instance, the assumption of perfect competition does not seem to hold in real world economies. Moreover, the production function may not exhibit constant returns to scale and the Cobb-Douglas functional form may not be entirely satisfactory. For instance, Dimitz (2001) uses a Constant Elasticity of Substitution (CES) production function, which is more general that the CobbDouglas, and allows the substitution elasticity among factors to differ from one. Furthermore, estimating the output gap with a PF approach entails using measures of the trend of the inputs, which are not straightforward to obtain. ${ }^{20}$ Moreover, as noted by Fernald (2014), productionfunction measures of potential output are inherently cyclical because investment is cyclical. Finally, the standard production function approach is a one sector model, but Basu and Fernald (2009) show that two-sector models -where one sector produces consumption goods and the other produces investment goods- fit the data much better, since they are able to capture the rapid technological change in the production of equipment goods.

\subsection{Aggregate supply and demand shocks. Blanchard and Quah (1989) [BQ]}

Blanchard and Quah (1989) interpret fluctuations in GDP and unemployment as due to two types of disturbances: disturbances with a permanent effect on output, mostly supply shocks, and disturbances that only have a transitory effect on output, mostly demand shocks. This interpretation of disturbances with permanent effects as supply shocks and disturbances with transitory effect as demand shocks is motivated by a traditional Keynesian view of fluctuations. $\mathrm{BQ}$ employ a simple model based on Fisher's nominal wage contracting theory. In their model, due to nominal rigidities, demand disturbances have short-run effects on output and unemployment, but these effects disappear over time. In the long-run, only supply shocks affect output. Neither of the disturbances have a long run impact on unemployment.

To identify structural disturbances they introduce a Structural Vector Autoregression (SVAR) with long-run identifying restrictions. This approach assumes that the vector of variables of interest $x_{t}$ has the following structural interpretation, which is based on economic theory: $x_{t}=d+S(L) \cdot \eta_{t}$ where $d$ is a $n x 1$ vector of deterministic components, $\eta_{t}$ is a $n x 1$ vector of structural shocks with $E \eta_{t}=0$ and $E \eta_{t} \eta_{t}^{\prime}=I_{n}$. The assumption that the variance-covariance matrix is the identity is simply a convenient normalisation. $S(L)$ shows the transmission mechanism through which structural disturbances affect the economy. Formally, it is a matrix polynomial in the lag operator L. $S(L)=\sum_{j=0}^{\infty} S_{j} L^{j}$. Blanchard and Quah (1989) introduce longrun identification restrictions. Heuristically, identification is achieved if the number of restrictions equals the number of unknowns in $S(0)$.

In their empirical application, BQ use a bivariate model and one of the series has a unit root. In that framework, independence of structural shocks imposes three restrictions on the four elements of $S(0)$. To identify their model, $\mathrm{BQ}$ additionally impose that demand disturbances only have a transitory effect on output $S_{12}(1)=0$.

20. Staiger et al. (1997) show that NAIRU estimates are fairly uncertain and great care is needed when using this measure in policy-making. 
Following estimation, a decomposition of output in terms of the structural disturbances is given by:

$$
\Delta y_{t}=d_{y}+S_{y}^{p}(L) \eta_{t}^{p}+S_{y}^{t}(L) \eta_{t}^{t}
$$

where $\eta_{t}^{p}$ is the vector of structural shocks with a permanent effect on output and $\eta_{t}^{t}$ is the vector of structural shocks with a transitory effect on output. The first difference of trend output is the sum of the first two terms of the right hand side. Thus, trend output corresponds to the permanent component of output. One advantage of this method is that trend or potential output is not restricted to be a simple random walk and will generally display richer dynamics. ${ }^{21}$

Some authors have criticised the $\mathrm{BQ}$ decomposition because it does not correctly identify supply and demand shocks, given that some supply disturbances have transitory effects on output and some disturbances may have a permanent effect on output. Furthermore, some care is needed to correctly interpret SVAR results. Indeed, Faust and Leeper (1997) point out some reasons why structural inferences under long-run identification restrictions may be unreliable. For instance, in finite samples, the long-run effect of shocks may be imprecisely estimated. Moreover, Fernald (2007) has shown that VARs identified with long-run restrictions are quite sensitive to controlling for breaks in labor productivity.

\subsection{Phillips curve models [PC]}

Potential output is a key element in price setting models built on the Phillips curve. According to this view, an excess of output over potential implies tight labour and product markets, so that inflation will tend to rise in the short-run, provided that inflation expectations and supply conditions remain unchanged. Conversely, when the output gap is negative and labour and product markets are slack, inflation will tend to fall in the short-run. In the short-run, the Phillips curve shows a positive relationship between the change in the price level and deviations of output relative to potential for a given expected inflation rate.

The idea of these estimation procedures is that the joint estimation of the Phillips curve and the output gap should provide more information that the univariate estimation of the output gap. The output gap is then determined as the one most consistent with observed inflation subject to the smoothness restrictions implicit in the stochastic trend specification of GDP. The fact that potential output and the output gap are not observable suggests the use of multivariate unobserved components models linking these concepts to observed variables. In order to identify the unobserved components, the framework requires that the stochastic process of potential output be specified and some restrictions on the correlation between innovations to unobserved variables and the innovation of the economic equation. A model is cast in statespace form and then a Kalman smoother is used to estimate its parameters and to derive the unobserved output gap series.

\subsubsection{TRADITIONAL PHILLIPS CURVES [TPC]}

Kuttner (1994) first suggests the use of a multivariate unobserved components model to estimate potential output. Specifically, this author uses a Phillips curve in which the current change of inflation is related to the lagged output gap and a vector of additional variables $z_{t}$ to capture the effects of temporary relative price shocks on inflation. The essence of traditional Phillips curve models of price adjustment is that the level of output relative to potential $\left(C_{t}^{T P C}\right)$ is systematically

21. The $B Q$ definition includes in the trend the dynamics of permanent structural shocks, thus allowing for the gradual absorption of technology shocks by the economy. 
related to inflation $\pi_{t}$ and a set of exogenous variables $z_{t}$, such as nominal oil prices or the exchange rate.

$$
\Delta \pi_{t}=\mu+\beta_{0} C_{t-1}^{T P C}\left(y_{t}\right)+\beta_{1} z_{t}+\varepsilon_{t}
$$

This accelerationist specification is consistent with a Phillips curve model in which expected inflation equals lagged inflation, $\beta_{0}$ is the slope of the Phillips curve and $\beta_{1}$ represents the elasticities of inflation with respect to exogenous variables.

To identify the model, Kuttner (1994) assumes that the output gap is an AR(2) process and potential output follows a random walk with drift. The output and inflation equations together form a bivariate unobserved components model that may be estimated by maximum likelihood through the use of the Kalman filter.

The method includes a fair amount of structural information while maintaining parsimony. The main advantages it offers is that it may be readily updated as fresh inflation and output data are released and no independent measure of the NAIRU is needed, nor does it require any subjective judgement. Additionally, it offers a measure of the time-varying uncertainty associated with the potential output series.

\subsubsection{NEW KEYNESIAN PHILLIPS CURVES [NKPC]}

In traditional formulations of the Phillips curve, inflation expectations are fully backward looking, so that expected inflation simply depends on lagged inflation. In contrast, in modern New Keynesian Phillips Curve models [NKPC], forward looking profit maximising firms set prices on the basis of expected marginal cost, so that current inflation depends on expected future inflation and the output gap. In practice, hybrid models, in which current inflation depends both on lagged and expected future inflation seem to provide a better description of the inflationary process.

Doménech and Gómez (2006) estimate a multivariate model including a NKPC. Expected inflation is generated endogenously within the model:

$$
\pi_{t}=\mu+\alpha E_{t}\left(\pi_{t+1}\right)+(1-\alpha) \pi_{t-1}+\beta_{0} C_{t-1}^{N K P C}\left(y_{t}\right)+\beta_{1} z_{t}+\varepsilon_{t}
$$

The model includes equations for the Phillips Curve, Okun's Law, and investment equation and the assumption that the output gap is an $\mathrm{AR}(2)$ process and potential output follows a random walk with drift. The model is estimated by maximum likelihood using a Kalman filter.

\subsection{Natural rate of interest [NRI]}

Laubach and Williams $(2003,2015)$ consider a multivariate model that jointly estimates the natural rate and the output gap, taking into account the comovements in inflation, output, and interest rates. The natural rate of interest changes over time owing to shifts in aggregate supply and demand. Specifically, the natural rate of interest, denoted $r_{t}^{*}$ is given by:

$$
r_{t}^{*}=c \Delta T_{t}^{N R I}\left(y_{t}\right)+z_{t}
$$

where $\Delta T_{t}^{N R I}\left(y_{t}\right)$ is the estimated trend growth rate of potential GDP that is assumed to be a random walk process, $z_{t}$ is an unobserved component that is also assumed to follow a random walk process, and $\mathrm{c}$ is an estimated coefficient that measures the influence of the trend growth rate on the natural rate of interest. The model is estimated using the Kalman filter and 
also uses an IS curve relating the output gap to its own lags and the lagged "real rate gap" -the difference between the actual real interest rate and the natural rate. The output gap is informed by a Phillips curve that relates core inflation to its own lags, the lagged output gap, and movements in the relative prices of oil and non-energy imports.

\subsection{Real Business Cycle models [RBC]}

Real business cycle (RBC) models are dynamic, stochastic general equilibrium models of the economy that generate empirical predictions for a wide array of macroeconomic variables. RBC models view aggregate economic variables as the outcomes of the rational decisions made by many individual agents acting to maximise their utility or profits subject to production possibilities and resource constraints. Moreover, the general equilibrium of the model is always fully specified.

A stylised RBC model is made by an economy populated by many identical agents that live forever. Each individual has to maximise his lifetime utility subject to the production technology and a sequence of resource constraints. Given the specific functional forms for the utility function and the production function and some initial conditions, it is possible to derive the optimal decisions of the individual for his consumption, work and investment decisions. This model (see King, Plosser and Rebelo (1988) for details) then predicts that all quantity variables (with the exception of work effort) grow at the same rate, which is given by the growth rate of technological progress. Therefore, the logarithms of the balanced-growth great ratios isolate two linearly independent cointegrating vectors. ${ }^{22}$

The starting point is the structural model $x_{t}=d+\breve{S}(L) \cdot \breve{\eta}_{t}$ where $\breve{\eta}_{t}$ is a nx1 vector of structural shocks with $E \breve{\eta}_{t}=0$ and a block diagonal variance covariance matrix $\Sigma_{\bar{\eta}}$, which is partitioned conformably with $\breve{\eta}_{t}=\left(\breve{\eta}_{t}^{p^{\prime}}, \breve{\eta}_{t}{ }^{\prime}\right)^{\prime}$, where $\breve{\eta}_{t}^{p}$ is a $p x 1$ vector of structural shocks with permanent effects, $\breve{\eta}_{t}^{t}$ is a $(n-p) x 1$ vector of structural disturbances with transitory effects. Permanent shocks are assumed to be orthogonal but transitory shocks may be correlated. Furthermore, the cointegration restrictions derived from the theoretical model impose constraints on the matrix of long-run multipliers $\breve{S}(1)$, which allow us to identify the permanent components.

Following estimation of the structural model, King et al. (1991) suggest employing a multivariate version of the $\mathrm{BN}$ decomposition.

$$
\begin{aligned}
& \Delta x_{1 t}=d_{1}+\breve{S}_{1}^{p}(1) \breve{\eta}_{t}^{p}+\dot{\vec{S}}_{1}^{p}(L) \breve{\eta}_{t}^{p}+\breve{S}_{1}^{t}(L) \breve{\eta}_{t}^{t} \\
& \text { where } \dot{\dot{S}}_{1}^{p}(L)=\sum_{j=0}^{\infty} \dot{\vec{S}}_{1 j}^{p} L^{j} \quad \dot{\vec{S}}_{1 j}^{p}=-\sum_{m=j+1}^{\infty} \breve{S}_{1 m}
\end{aligned}
$$

Its interpretation in terms of a trend-cycle decomposition is as follows. The sum of the first two terms on the right hand side represents (the first difference of) the trend, while the sum of the third and fourth represents (the first difference of) the cyclical component. Note that the trend is a random walk with drift, a feature that has been criticised above. This contrasts with BQ's approach, which includes the diffusion process associated with permanent shocks in trend output. 
It should be emphasised that although the economic theory which motivates the identifying restrictions is different in BQ's and King et al. (1991)'s approaches, the econometric methodology is, broadly speaking, the same. ${ }^{23}$

\subsection{Dynamic Stochastic General Equilibrium models [DSGE]}

In recent years, Dynamic Stochastic General Equilibrium (DSGE) models have become widely used to project the economy and to derive policy implications. This class of models combine Keynesian and Real Business Cycle features in the sense that wages and prices are sticky and classical theory explains the long-run. This class of models typically incorporates various other features such as habit formation, costs of adjustment in capital accumulation and variable capacity utilization. They are generally estimated with Bayesian techniques using a limited number of variables [see e.g. Smets and Wouters (2003), Edge et al. (2008) or Fueki et al. (2016)].

DSGE models allow us to consider three different notions of potential output [Vetlov et al. (2011)]. First, the trend level of output is equal to the sequence of permanent stochastic technology shocks that characterize the balanced-growth part of the model. Second, the efficient level of output is the level of GDP that would prevail if goods and labour markets were perfectly competitive. Third, the natural level of output is the level of output under flexible wages and prices and imperfectly competitive markets. Estimates of trend level of output using DSGE models focus on the long-run and are typically close to those obtained from conventional approaches. In contrast, efficient and natural levels have a business cycle dimension related to the shocks that push the economy temporarily away from the steady state, so are generally more volatile. Their use depends on the aim of the analysis. From the point of view of inflation, interest should focus on the natural output gap, since under certain assumptions this measure of the output gap is a key driver of inflation. From the point of view of welfare, policymakers should aim at stabilising the efficient output gap. ${ }^{24}$

Among the advantages of DSGE models, they allow for a deeper structural interpretation. The joint estimation of potential output and structural shocks within the general equilibrium framework allows conducting a quantitative and internally consistent assessment of inflation pressures and a normative evaluation of alternative monetary measures. Among the drawbacks, it has been pointed out that the flexible-price and natural rate gaps are highly dependent on modelling assumptions [Kiley (2013)].

23. This is best seen by rewriting the model of King et al. (1991) in terms of stationary variables. The productivity shock has a long-run effect on output, but no long-run effect on the consumption and investment ratios.

24. Unless the so-called "divine coincidence" holds, stabilizing the efficient output gap is not the same as stabilising the natural output gap. 
In this paper, we examine different approaches used in the literature to estimate potential or trend output and the output gap, highlighting their advantages and drawbacks. Potential output and the output gap are unobservable and an objective definition of the business cycle does not exist. Both reasons have led to a proliferation of techniques for measuring business cycles. However, different techniques employ, explicitly or implicitly, different hypotheses, of either statistical or theoretical nature. Comparisons of techniques should take this fact into account. Tables 1 and 2 summarize some of the main characteristics of the univariate and multivariate methods presented in this paper.

Table 1

Univariate estimation methods

\begin{tabular}{|c|c|c|c|c|}
\hline & Model based & $\begin{array}{l}\text { Decision } \\
\text { variables }\end{array}$ & Complexity & $\begin{array}{c}\text { Need or } \\
\text { advisability of } \\
\text { using forecast }\end{array}$ \\
\hline Hodrick \& Prescott & No & $\begin{array}{l}\text { Smoothness } \\
\text { parameter }\end{array}$ & Low & Yes \\
\hline Baxter \& King & No & $\begin{array}{l}\text { Pass band } \\
\text { Filter length }\end{array}$ & Low & Yes \\
\hline Butterworth filtering & No & $\begin{array}{l}\text { Pass band } \\
\text { Filter length }\end{array}$ & High & Yes \\
\hline $\begin{array}{l}\text { Wavelet-based } \\
\text { methods }\end{array}$ & No & Wavelet basis & High & Yes \\
\hline Linear detrending & Yes & None & Low & No \\
\hline Beveridge \& Nelson & Yes & ARIMA model & High & Yes \\
\hline Structural time series & Yes & STS model & High & No \\
\hline Hamilton & Yes & $\begin{array}{c}\text { Regime switching } \\
\text { model }\end{array}$ & High & No \\
\hline Kim \& Nelson & Yes & $\begin{array}{l}\text { Regime switching } \\
\text { model }\end{array}$ & High & No \\
\hline
\end{tabular}

It is convenient to classify existing approaches to estimate the output gap into different groups, according to the criteria used. Univariate methods are based on statistical assumptions, which define what is considered to be the output gap or trend output. These procedures could be summarised as follows: on the positive side, they are generally simple procedures that do not require judgmental assumptions about the structure of the economy. As a consequence, they can be applied to a large number of countries in a homogeneous and timely way. Nevertheless, the main disadvantage of these methods is the lack of economic theory criteria underlying their application, and the fact that they do not incorporate potentially useful information on some other variables into the analysis. 
On the contrary, the use of multivariate methods within the context of a model based on economic theory is attractive. Multivariate approaches exploit economic theory to estimate potential or trend output, a feature that is certainly attractive. However, it has to be acknowledged that views on the structure of the economy are likely to differ widely across researchers. Moreover, cross-country comparisons have to be made with due care due to differences in the economic structure of different countries.

Table 2

\section{Multivariate estimation methods}

\begin{tabular}{|c|c|c|c|}
\hline & $\begin{array}{l}\text { Underlying } \\
\text { economic theory }\end{array}$ & Decision variables & Complexity \\
\hline Okun's law & Okun's law & VAR model & Medium \\
\hline Production function & Production function & $\begin{array}{l}\text { Production function } \\
\text { Cyclically adjusted inputs }\end{array}$ & High \\
\hline Blanchard \& Quah & $\begin{array}{c}\text { Supply and demand } \\
\text { shocks }\end{array}$ & SVAR model & High \\
\hline Phillips curve & Phillis curve & $\begin{array}{l}\text { Output gap time series } \\
\text { process }\end{array}$ & High \\
\hline $\begin{array}{l}\text { Natural rate } \\
\text { of interest }\end{array}$ & $\begin{array}{l}\text { Natural rate } \\
\text { of interest }\end{array}$ & $\begin{array}{l}\text { Lags in the Phillips curve, } \\
\text { Output gap time series } \\
\text { process }\end{array}$ & High \\
\hline RBC model & General equilibrium & VECM model & High \\
\hline DSGE model & General equilibrium & Model specification & High \\
\hline
\end{tabular}

Our main conclusion is that the different methods that have been proposed in the literature have their particular advantages and disadvantages and none of them takes priority over the rest. Therefore, it seems adequate to examine several of them in order to obtain a more reliable description of the state of the cyclical position of the economy. However, nowadays the most widespread technique in policy institutions is the production function approach and DSGE methods are increasingly being used. While time-specific circumstances may make it advisable to focus on a particular measure, it is nonetheless true that diagnosis of the cyclical position gains in solidity insofar as different measures convey the same message. This is especially important if these measures play some role in economic policy decision-making. 


\section{REFERENCES}

AGUIAR-CONRARIA, L. and M.J. SOARES (2011). "Business cycle synchronization and the Euro: a wavelet analysis," Journal of Macroeconomics, 33(3):477-489.

APEL, M. and P. JANSSON (1999). "A theory consistent system approach for estimating potential output and the NAIRU," Economics Letters. 64:271-275.

BAXTER, M. and R. G. KING (1999). "Measuring Business Cycles. Approximate Band-Pass Filters for Economic Time Series," The Review of Economics and Statistics, 81(4):575-593.

BASU, S. and J. FERNALD (2009). "What Do We Know and Not Know About Potential Output?," Federal Reserve Bank of St . Louis Review. July/August:187-213.

BEVERIDGE, S. and NELSON, C.R. (1981). "A new approach to decomposition of economic time series into permanent and transitory components with particular attention to measurement of the 'business cycle'," Journal of Monetary Economics, 7:151-174.

BLANCHARD, O. J. and D. QUAH (1989). "The Dynamic Effect of Aggregate Demand and Supply Disturbances," The American Economic Review, 79(4):655-673.

BURNS, A.M. and W. C. MITCHELL (1946). Measuring Business Cycles. National Bureau of Economic Research.

CANOVA, F. (1998). "Detrending and business cycle facts," Journal of Monetary Economics, 41:475-512.

COGLEY, T. and J.M. NASON (1995). "Effects of the Hodrick-Prescott filter on trend and difference stationary time series. Implications for business cycle research," Journal of Economic Dynamics and Control, 19:253-278.

COTIS, J. P.; ELMESKOV, J. and A. MOUROUGANE (2004). Estimates of potential output: benefits and pitfalls from a policy perspective, in L. Reichlin (ed.) The Euro Area Business Cycle: Stylized Facts and Measurement Issues. Center for Economic Policy Research.

CHRISTIANO, L. J. and FITZGERALD, T. J. (2003). "The band pass filter," International Economic Review. 44(2):435-465.

DIMITZ, M. A. (2001). "Output gaps in European monetary union. New Insights from Input Augmentation in the Technological Progress," Economic Series 102, Institute for Advanced Studies.

DONOHO, D. (1993). Non-linear Wavelets Methods for Recovery of Signals, Densities and Spectra form Indirect and Noisy Data, in Daubechies (ed.) Proceedings of Symposia in Applied Mathematics. American Mathematical Society, 163-205.

DRAKE, L. and T.C. MILLS (2010). "Trends and cycles in Euro area real GDP," Applied Economics, 2010, 42:1397-1401.

EDGE, R.; KILEY, M. T. and J-P. LAFORTE. (2008). "An estimated DSGE model of the US economy with an application to natural rate measures," Journal of Economic Dynamics and Control, 32:2512-2535.

ENGLUND, P.; PERSSON, T. and L.E.O. SVENSSON (1992). "Swedish business cycles: 1861-1988," Journal of Monetary Economics, 30(2):251-276.

EVANS, G. (1989). "Output and unemployment dynamics in the United States 1950-85," Journal of Applied Econometrics 4:213-237.

EVANS, G. and L. REICHLIN (1994). "Information, forecasts, and the measurement of the business cycle," Journal of Monetary Economics. 33:233-254.

FAUST, J. and E. M. LEEPER (1997). "When Do Long-Run Identifying Restrictions Give Reliable Results?," Journal of Business and Economic Statistics, 15(3):345-353.

FERNALD, J. G. (2007). "Trend breaks, long-run restrictions, and contractionary technology improvements," Journal of Monetary Economics, 54(8):2467-2485.

FERNALD, J. G. (2014). "Productivity and Potential Output before, during, and after the Great Recession," NBER Macroeconomics Annual 29(1):1-51.

FRIEDMAN, M. (1964). Monetary Studies of the National Bureau, 44 ${ }^{\text {th }}$ Annual Report, 7-25. NBER

FRIEDMAN, M. (1993). "The plucking model of business fluctuations revisited," Economic Enquiry, 31:171-177.

FUEKI, T.; FUKUNAGA, I.; ICHIUE, H. and T. SHIROTA (2016). "Measuring Potential Growth with an Estimated DSGE Model of Japan's Economy," International Journal of Central Banking, 12(1):1-32.

GÓMEZ, V. (2001). "The use of Butterworth filters for trend and cycle estimation in economic time series," Journal of Business and Economic Statistics, 19(3):365-373.

HAMILTON, J. D. (1989). "A new approach to the economic analysis of nonstationary time series and the business cycle," Econometrica, 57:357-384.

HARVEY, A. C. (1985). "Trends and cycles in macroeconomic time series," Journal of Business and Economic Statistics, 3(3):216-227

HARVEY, A. C. and A. JAEGER (1993). "Detrending, stylized facts and the business cycle," Journal of Applied Econometrics, 8:231-247.

HARVEY, A. C. and T. M. TRIMBUR (2003). "General model-based filters for extracting cycles and trends in economic time series," Review of Economics and Statistics, 85(2):244-255

HARVEY, A.; TRIMBUR, T. and H. K. VAN DIJK (2007). "Trends and cycles in economic time series: A Bayesian approach," Journal of Econometrics. 127(2):618-649.

HASSLER, J.; LUNDVIK, P.; PERSSON, T. and P. SÖDERLIND (1994). The Swedish Business Cycle. Stylized Facts over 130 years, in Berstrom, V. and A. Vredin (eds.) Measuring and interpreting business cycles, Oxford University Press.

HODRICK, R.J. and E.C. PRESCOTT (1997). "Postwar U.S. Business Cycles: An Empirical Investigation," Journal of Money, Credit and Banking, 29(1):1-16

KAISER, R. and A. MARAVALL (2001). Measuring Business Cycles in Economic Time series. Springer Verlag.

KILEY, M. T. (2013). "Output gaps," Journal of Macroeconomics. 37:1-18.

KIM, C. J.; Morley, G.C. and J. Piger (2005). "Nonlinearity and the permanent effect of recessions," Journal of Applied Econometrics. 20:291-309. 
KIM, C-J. and C. R. NELSON (1999). "Friedman's plucking model of business fluctuations: tests and estimates of permanent and transitory components," Journal of Money, Credit and Banking, 31:317-34.

KING, R. G.; Plosser, C.I. and S.T. Rebelo (1988). "Production, growth and business cycles II. New Directions," Journal of Monetary Economics, 21:309-341.

KING, R. G.; PLOSSER, C. I.; STOCK, J. H. and M. W. WATSON (1991). "Stochastic Trends and Economic Fluctuations," The American Economic Review, 81(4):819-840.

KING, R.G and S. T. REBELO (1993). "Low frequency filtering and real business cycles," Journal of Economic Dynamics and Control, 17:207-231.

KUTTNER, K. N. (1994). "Estimating potential output as a latent variable," Journal of Business and Economic Statistics, 12(3):361-368.

LAUBACH, T. and J. C. WILLIAMS (2003). "Measuring the Natural Rate of Interest," Review of Economics and Statistics, 85(4):1063-1070.

LAUBACH, T. and J. C. WILLIAMS (2015). Measuring the Natural Rate of Interest Redux, Federal Reserve Bank of San Francisco Working Paper 2015-16.

MARAVALL, A. and A. DEL RIO (2007). Temporal aggregation, systematic sampling and the Hodrick-Prescott filter, Documento de Trabajo $n^{\circ} 0728$. Banco de España.

MISE, E.; KIM, T-H. and P. NEWBOLD (2005). "On suboptimality of the Hodrick-Prescott filter at time series endpoints," Journal of Macroeconomics. 27(1):53-67.

MORLEY, G. C. (2011). "The two interpretations of the Beveridge-Nelson decomposition," Macroeconomic Dynamics, 15:419-439.

MORLEY, G. C.; NELSON, C.R. and E. ZIVOT (2003). "Why Are the Beveridge-Nelson and Unobserved-Components Decompositions of GDP So Different?," Review of Economics and Statistics. 85(2): 235-243.

MURRAY, C. J. (2003). "Cyclical properties of Baxter-King filtered time series," Review of Economics and Statistics, 85(2):472-476.

PRESCOTT, E. C. (1986). "Theory Ahead of Business Cycle Measurement," Quarterly Review, Federal Reserve of Minneapolis, Fall, 9-22.

PROIETTI, T. and A. HARVEY (2000). "A Beveridge-Nelson smoother," Economics Letters, 67:139-146.

SINCLAIR, T. M. (2010). "Asymmetry in the business cycle: Friedman's plucking model with correlated innovations," Studies in Nonlinear Dynamics and Econometrics, 14(1), Article 3.

SMETS, F. and R. WOUTERS (2003). "An estimated Dynamic Stochastic General Equilibrium model of the euro area," Journal of the European Economic Association, 1:1123-1175.

STAIGER, D.; STOCK, J. H. and M. W. WATSON (1997). "The NAIRU, unemployment, and monetary policy," Journal of Economic Perspectives, 11(1):33-49.

STOCK, J. H. and M. W. WATSON (1999). Business Cycle Fluctuations in US Macroeconomic Time Series, in Taylor, J. B. and Woodford, M. (eds.) Handbook of Macroeconomics. North-Holland, 3-64.

STOCK, J. H., and M. W. WATSON (2005). "Understanding Changes in International Business Cycle Dynamics," Journal of the European Economic Association, 3(5):968-1006.

SUMMERS, L. (2014). "U.S. Economic Prospects: Secular Stagnation, Hysteresis, and the Zero Lower Bound," Business Economics, 49(2):65-73.

TIWARI, A. K.; OROS, C. and C. T. ALBULESCU (2014). "Revisiting the inflation-output gap relationship for France using a wavelet transform approach," Economic Modelling, 37:464-475.

TRIMBUR, T. M. (2006). "Detrending economic time series: A Bayesian generalization of the Hodrick- Prescott filter," Journal of Forecasting, 25:247-273.

VALLE E. AZEVEDO, J.; KOOPMAN, S. J. and A. RUA (2006). "Tracking the Business Cycle of the Euro Area," Journal of Business and Economic Statistics, 24(3):278-290.

VETLOV, I., HLÉDIK, T.; JONSSON, M.; KUCSERA, H. and M. Pisani (2011). Potential output in DSGE models, Working Paper Series 1351, European Central Bank. 


\title{
BANCO DE ESPAÑA PUBLICATIONS
}

\author{
WORKING PAPERS
}

1601 CHRISTIAN CASTRO, ÁNGEL ESTRADA and JORGE MARTÍNEZ: The countercyclical capital buffer in Spain: an analysis of key guiding indicators.

1602 TRINO-MANUEL ÑíGUEZ and JAVIER PEROTE: Multivariate moments expansion density: application of the dynamic equicorrelation model.

1603 ALBERTO FUERTES and JOSÉ MARÍA SERENA: How firms borrow in international bond markets: securities regulation and market segmentation.

1604 ENRIQUE ALBEROLA, IVÁN KATARYNIUK, ÁNGEL MELGUIZO and RENÉ OROZCO: Fiscal policy and the cycle in Latin America: the role of financing conditions and fiscal rules.

1605 ANA LAMO, ENRIQUE MORAL-BENITO and JAVIER J. PÉREZ: Does slack influence public and private labour market interactions?

1606 FRUCTUOSO BORRALLO, IGNACIO HERNANDO and JAVIER VALLÉS: The effects of US unconventional monetary policies in Latin America.

1607 VINCENZO MERELLA and DANIEL SANTABÁRBARA: Do the rich (really) consume higher-quality goods? Evidence from international trade data.

1608 CARMEN BROTO and MATÍAS LAMAS: Measuring market liquidity in US fixed income markets: a new synthetic indicator.

1609 MANUEL GARCÍA-SANTANA, ENRIQUE MORAL-BENITO, JOSEP PIJOAN-MAS and ROBERTO RAMOS: Growing like Spain: 1995-2007

1610 MIGUEL GARCÍA-POSADA and RAQUEL VEGAS: Las reformas de la Ley Concursal durante la Gran Recesión.

1611 LUNA AZAHARA ROMO GONZÁLEZ: The drivers of European banks' US dollar debt issuance: opportunistic funding in times of crisis?

1612 CELESTINO GIRÓN, MARTA MORANO, ENRIQUE M. QUILIS, DANIEL SANTABÁRBARA and CARLOS TORREGROSA: Modelling interest payments for macroeconomic assessment.

1613 ENRIQUE MORAL-BENITO: Growing by learning: firm-level evidence on the size-productivity nexus.

1614 JAIME MARTÍNEZ-MARTíN: Breaking down world trade elasticities: a panel ECM approach.

1615 ALESSANDRO GALESI and OMAR RACHEDI: Structural transformation, services deepening, and the transmission of monetary policy.

1616 BING XU, ADRIAN VAN RIXTEL and HONGLIN WANG: Do banks extract informational rents through collateral?

1617 MIHÁLY TAMÁS BORSI: Credit contractions and unemployment.

1618 MIHÁLY TAMÁS BORSI: Fiscal multipliers across the credit cycle.

1619 GABRIELE FIORENTINI, ALESSANDRO GALESI and ENRIQUE SENTANA: A spectral EM algorithm for dynamic factor models.

1620 FRANCISCO MARTÍ and JAVIER J. PÉREZ: Spanish public finances through the financial crisis.

1621 ADRIAN VAN RIXTEL, LUNA ROMO GONZÁLEZ and JING YANG: The determinants of long-term debt issuance by European banks: evidence of two crises.

1622 JAVIER ANDRÉS, ÓSCAR ARCE and CARLOS THOMAS: When fiscal consolidation meets private deleveraging.

1623 CARLOS SANZ: The effect of electoral systems on voter turnout: evidence from a natural experiment.

1624 GALO NUÑO and CARLOS THOMAS: Optimal monetary policy with heterogeneous agents.

1625 MARÍA DOLORES GADEA, ANA GÓMEZ-LOSCOS and ANTONIO MONTAÑÉS: Oil price and economic growth: a long story?

1626 PAUL DE GRAUWE and EDDIE GERBA: Stock market cycles and supply side dynamics: two worlds, one vision?

1627 RICARDO GIMENO and EVA ORTEGA: The evolution of inflation expectations in euro area markets.

1628 SUSANA PÁRRAGA RODRÍGUEZ: The dynamic effect of public expenditure shocks in the United States.

1629 SUSANA PÁRRAGA RODRÍGUEZ: The aggregate effects of government incometransfer shocks - EU evidence.

1630 JUAN S. MORA-SANGUINETTI, MARTA MARTÍNEZ-MATUTE and MIGUEL GARCÍA-POSADA: Credit, crisis and contract enforcement: evidence from the Spanish loan market. 
1631 PABLO BURRIEL and ALESSANDRO GALESI: Uncovering the heterogeneous effects of ECB unconventional monetary policies across euro area countries.

1632 MAR DELGADO TÉLLEZ, VÍCTOR D. LLEDÓ and JAVIER J. PÉREZ: On the determinants of fiscal non-compliance: an empirical analysis of Spain's regions.

1633 OMAR RACHEDI: Portfolio rebalancing and asset pricing with heterogeneous inattention.

1634 JUAN DE LUCIO, RAÚL MÍNGUEZ, ASIER MINONDO and FRANCISCO REQUENA: The variation of export prices across and within firms.

1635 JUAN FRANCISCO JIMENO, AITOR LACUESTA, MARTA MARTÍNEZ-MATUTE and ERNESTO VILLANUEVA: Education, labour market experience and cognitive skills: evidence from PIAAC.

1701 JAVIER ANDRÉS, JAVIER J. PÉREZ and JUAN A. ROJAS: Implicit public debt thresholds: an empirical exercise for the case of Spain.

1702 LUIS J. ÁLVAREZ: Business cycle estimation with high-pass and band-pass local polynomial regression.

1703 ENRIQUE MORAL-BENITO, PAUL ALLISON and RICHARD WILLIAMS: Dynamic panel data modelling using maximum likelihood: an alternative to Arellano-Bond.

1704 MIKEL BEDAYO: Creating associations as a substitute for direct bank credit. Evidence from Belgium.

1705 MARÍA DOLORES GADEA-RIVAS, ANA GÓMEZ-LOSCOS and DANILO LEIVA-LEON: The evolution of regional economic interlinkages in Europe.

1706 ESTEBAN GARCÍA-MIRALLES: The crucial role of social welfare criteria for optimal inheritance taxation.

1707 MÓNICA CORREA-LÓPEZ and RAFAEL DOMÉNECH: Service regulations, input prices and export volumes: evidence from a panel of manufacturing firms.

1708 MARÍA DOLORES GADEA, ANA GÓMEZ-LOSCOS and GABRIEL PÉREZ-QUIRÓS: Dissecting US recoveries.

1709 CARLOS SANZ: Direct democracy and government size: evidence from Spain.

1710 HENRIQUE S. BASSO and JAMES COSTAIN: Fiscal delegation in a monetary union: instrument assignment and stabilization properties.

1711 IVÁN KATARYNIUK and JAIME MARTÍNEZ-MARTÍN: TFP growth and commodity prices in emerging economies.

1712 SEBASTIAN GECHERT, CHRISTOPH PAETZ and PALOMA VILLANUEVA: Top-down vs. bottom-up? Reconciling the effects of tax and transfer shocks on output.

1713 KNUT ARE AASTVEIT, FRANCESCO FURLANETTO and FRANCESCA LORIA: Has the Fed responded to house and stock prices? A time-varying analysis

1714 FÁTIMA HERRANZ GONZÁLEZ and CARMEN MARTÍNEZ-CARRASCAL: The impact of firms' financial position on fixed investment and employment. An analysis for Spain.

1715 SERGIO MAYORDOMO, ANTONIO MORENO, STEVEN ONGENA and MARÍA RODRÍGUEZ-MORENO: "Keeping it personal" or "getting real"? On the drivers and effectiveness of personal versus real loan guarantees.

1716 FRANCESCO FURLANETTO and ØRJAN ROBSTAD: Immigration and the macroeconomy: some new empirical evidence.

1717 ALBERTO FUERTES: Exchange rate regime and external adjustment: an empirical investigation for the U.S.

1718 CRISTINA GUILLAMÓN, ENRIQUE MORAL-BENITO and SERGIO PUENTE: High growth firms in employment and productivity: dynamic interactions and the role of financial constraints.

1719 PAULO SOARES ESTEVES and ELVIRA PRADES: On domestic demand and export performance in the euro area countries: does export concentration matter?

1720 LUIS J. ÁLVAREZ and ANA GÓMEZ-LOSCOS: A menu on output gap estimation methods.

BANCODEESPAÑA Eurosistema
Unidad de Servicios Auxiliares

Alcalá, 48 - 28014 Madrid

E-mail: publicaciones@bde.es www.bde.es 